удК 368.023.2

М. Н. Степанова

Байкальский государственный университет, 2. Иркутск, Российская Федерация

\title{
ПРАВОВЫЕ РИСКИ ОБЩЕСТВ ВЗАИМНОГО СТРАХОВАНИЯ: ПОНЯТИЕ И ОСОБЕННОСТИ
}

\begin{abstract}
АНнотАция. Общества взаимного страхования - институциональные субъекты, обладающие рядом организационно-правовых особенностей, определяющих условия их деятельности на страховом рынке. Правовые риски, которым они подвержены, также специфичны. Их идентификация является важным этапом риск-менеджмента, осуществляемого в рамках системы внутреннего контроля. Вместе с тем, анализ современной экономической литературы показал, что проблемам, связанным с подверженностью деятельности обществ взаимного страхования рискам, уделяется необоснованно мало внимания, а правовые риски не рассматриваются вообще. Однако данный аспект деятельности обществ взаимного страхования представляется весьма актуальным. В связи с этим, в статье доказывается необходимость выявления правовых рисков, присущих деятельности обществ взаимного страхования, исследуются их основные виды и факторы возникновения. Особое внимание в работе уделяется выявлению особенностей правовых рисков обществ взаимного страхования, даются рекомендации по минимизации наиболее актуальных из них.

КЛЮЧЕВЫЕ СЛОВА. Общество взаимного страхования; взаимное страхование; правовые риски; страхование; договорные риски; внешние риски; внутренние риски. ИНФОРМАЦИЯ О СТАТЬЕ. Дата поступления 18 июля 2017 г.; дата принятия к печати 5 июля 2017 г.; дата онлайн-размещения 25 октября 2017 г.
\end{abstract}

M. N. Stepanova Baikal State University, Irkutsk, Russian Federation

\section{LEGAL RISKS OF MUTUAL INSURANCE COMPANIES: CONCEPT AND FEATURES}

\begin{abstract}
Mutual insurance companies are institutional entities that have a number of organizational and legal features that determine the conditions of their activity in the insurance market. The legal risks to which they are exposed are also specific. Their identification is an important stage of risk management carried out within the framework of the internal control system. With that, analysis of the current economic literature has shown that the problems connected with the mutual insurance societies subject to risks are given a groundlessly little attention, while the legal risks are not examined at all. Yet, this aspect of the mutual insurance companies' activities appears rather topical. In this regard, the article proves the necessity of identifying the legal risks inherent to the mutual insurance societies' activities, investigates their major types and factors of emergence. The paper pays a special attention to identifying features of the mutual insurance companies' legal risks, gives recommendations concerning minimizing the most topical ones.
\end{abstract}

KEYWORDS. Mutual insurance companies; mutual insurance; legal risks; insurance; ccontractual risks; external risks; internal risks.

ARTICLE INFO. Received July 18, 2017; accepted July 5, 2017; available online October 25, 2017.

Общества взаимного страхования (далее по тексту - OBC), являясь институциональными субъектами с рядом организационно-правовых особенностей и особыми целями пребывания на финансовом рынке, тем не менее, являются его полноправными участниками [1], несмотря на существующую в научной литературе

(C) M. H. Cтепанова, 2017

\section{Baikal Research Journal}


неоднозначность оценки выполняемой ими роли [2]. Их правовое положение и условия деятельности весьма специфичны [3], внешнее окружение сложное, подвижное и весьма неопределенное - именно этим определяется малочисленность данной категории страховщиков на российском рынке страховых услуг, несмотря на максимальную транспарентность внутренней среды, благоприятной для выполнения поставленных членами общества задач.

В силу особенностей обеспечения финансовой устойчивости осуществляемых операций и низкого финансового потенциала отечественных обществ взаимного страхования, равновесие таких локальных хозяйствующих структур в большей мере подвержено изменениям на макро- и микроуровнях, несмотря на относительный уровень самостоятельности в принятии управленческих решений и постоянное нахождение в зоне солидарной ответственности по имеющимся обязательствам. Возможность реализации большей части рисков в нестабильной экономической среде неподконтрольна обществам взаимного страхования как субъектам управленческих решений, что приводит к необходимости развития их способностей приспособить управляемую систему к изменениям внешних условий, сохраняя при этом эффективность функционирования.

Очевидно, что общества взаимного страхования как хозяйствующие субъекты с инверсионной цикличностью должны учитывать разнообразные риски, которым они подвергаются в процессе своей деятельности, оценивать их и использовать результаты этой оценки для минимизации вероятности их реализации. Одной из разновидностей таких рисков являются так называемые правовые риски. $\mathbf{K}$ сожалению, правовым рискам в страховании практически не уделяется должного внимания ни в теоретическом плане, ни в практическом, хотя они могут привести к последствиям, не менее серьезным, чем, к примеру, рыночные риски. Нами были обобщены имеющиеся в доступных источниках различные точки зрения на суть изучаемой дефиниции тех, кто связан с данной категорией в силу выполняемых профессиональных задач и тех, для кого правовой риск как категория являлся предметом диссертационного исследования [4]. Отметим, что авторы многих публикаций отмечают сложность в определении понятия «правовой риск» и зачастую сводят его к опасностям, убыткам или ошибке, что, по нашему мнению, некорректно. Мы считаем, что под правовыми рисками, в том числе, имеющими место быть в деятельности обществ взаимного страхования, стоит понимать вероятность возникновения негативных последствий в деятельности организации из-за нарушений, допущенных при составлении, исполнении и применении юридических документов, ее сопровождающих. При этом, возможность возникновения потерь может быть исключена или уменьшена с использованием правовых инструментов. Под юридическими документами мы традиционно понимаем документы, содержащие правовую информацию и порождающие юридические последствия и финансовую ответственность. $К$ ним относят нормативно-правовые акты, правореализационные и правоприменительные документы, а также документы, фиксирующие юридические факты.

Возникновение правовых рисков обусловлено наличием как внутренних, так и внешних факторов. Вместе с тем, специфика деятельности обществ взаимного страхования такова, что большую угрозу для их деятельности могут представлять именно внешние правовые риски. Среди них наиболее актуальны законодательные риски, которые включают в себя риски изменения законодательства, а также риски правоприменительной практики. Здесь стоит отметить, что правовой основой создания обществ взаимного страхования послужила введенная в действие 1 марта 1996 года часть вторая Гражданского кодекса РФ: ст. 968 было установлено право граждан и юридических лиц «...страховать свое имущество и

\section{Baikal Research Journal}

электронный научный журнал Байкальского государственного университета 
иные имущественные интересы, указанные в пункте 2 статьи 929 настоящего Кодекса, на взаимной основе путем объединения в обществах взаимного страхования необходимых для этого средств». Таким образом, Гражданским кодексом была определена организационная форма осуществления взаимного страхования - это общества взаимного страхования. Федеральный закон от 27.11.1992 № 4015-1 «Об организации страхового дела в Российской Федерации» придал обществам взаимного страхования статус страховщика (статья 6) и отнес к субъектам страхового дела (статья 4.1). Федеральный закон от 29.11.2007 № 286-ФЗ «О взаимном страховании" установил особенности правового положения обществ, условия их деятельности, определил права и обязанности членов общества. Такова нормативно-правовая база взаимного страхования. $К$ обществам взаимного страхования в полной мере применимы также правовые нормы, содержащиеся в иных источниках права и относящиеся к регулированию страховых правоотношений, за исключением случаев, когда такие нормы или законодательные акты содержат специальные изъятия, ограничивающие их применение к деятельности ОВС. Казалось бы, нормативно-правовая база взаимного страхования сформирована и достаточно стабильна. Однако, утверждать то, что законодательные риски для OBC маловероятны, не стоит: до сих пор детально не проработаны вопросы обеспечения финансовой устойчивости обществ. Между тем, это особая зона рисков для всех участников отечественного рынка [5, с. 138], [6]. Безусловно, в идеальной деловой среде банкротство ОВС маловероятно, так как возможность внесения членами общества дополнительных средств предполагает наличие стабильного финансового источника: согласно статьи 123.3 ГК РФ (часть первая) и п. 3 статьи 18 Федерального закона "О взаимном страховании», образовавшиеся убытки члены общества обязаны покрыть, в том числе путем внесения дополнительных взносов. Однако, может иметь место существенное снижение платежеспособности членов общества и даже при субсидиарной ответственности по страховым обязательствам в условиях системного финансового кризиса и малочисленности самого общества фактически это может привести к неисполнению или ненадлежащему исполнению обязательств по выплатам. Отсутствие регламентируемой нижней границы снижения страховых взносов, предусмотренного статьей 19 Федерального закона «О взаимном страховании» и минимального уровня принадлежащего обществу имущества ставит под угрозу исполнение страховых обязательств перед членами общества и третьими лицами в случае реализации рисков, влекущих крупные убытки. По нашему мнению, в законодательство о взаимном страховании необходимо внести условие, обязывающее ОВС обладать гарантией исполнения обязательств в форме банковской гарантии или наличия собственных средств в размере не менее определенного размера, зависящего от максимального объема принимаемой ответственности, размещенных в денежные средства.

Еще одной зоной законодательных рисков ОВС может стать решение о необходимости обязательного актуарного оценивания деятельности ОВС ответственным актуарием исключительно на основании трудового договора, как в настоящее время это происходит в случае с организацией внутреннего аудита - это может привести к росту затрат общества и необходимости поиска дополнительных источников их финансирования. Привлечение субъекта актуарной деятельности на основании гражданско-правового договора, естественно, более экономично для ОВС, особенно если оно малочисленно, но даже это не всегда оправданно. Требование же об обязательном наличии актуария в штате ОВС может повлечь за собой не только финансовые риски, но и организационные, особенно на стадии создания общества.

Большинство компаний, строя свою деятельность в соответствии с действующим законодательством, отслеживает любые изменения в нем и своевременно на

\section{Baikal Research Journal}

электронный научный журнал Байкальского государственного университета 
них реагирует, а также стремится к активному взаимодействию с регулирующими органами в вопросах интерпретации норм законодательства. Однако не всегда существует возможность спрогнозировать изменение законодательства в будущем и это порождает соответствующий риск. Для ОВС это пока прогнозируемого, поскольку возможность внесения поправок в действующее страховое законодательство обсуждается публично, а сами поправки инициируются Национальной ассоциацией обществ взаимного страхования, что означает возможность создания более благоприятных условий для деятельности ОВС и устранение имеющихся в законодательстве противоречий.

Наибольшую угрозу может представлять вмешательство в этот процесс страховых компаний, лоббирующих свои интересы и претендующих на определенные сегменты рынка, обслуживаемые ОВС или перспективные для них (как, например, личное страхование, которым ОВС в настоящее время заниматься не могут). В связи с этим, думается, что для ОВС наиболее актуальным может быт лишь изменение той части законодательства, которая касается требований обеспечения финансовой устойчивости и платежеспособности и реализации соответствующих надзорных мер со стороны регулятора.

К законодательным рискам относят также риски правоприменительной практики. Как справедливо замечено В.М. Бартош, «особенности организации страхования на началах взаимности (цель создания ОВС и механизм достижения) ставят перед правоприменителем множество вопросов, не имеющих пока однозначных ответов ни в теории, ни в российском гражданском законодательстве, ни в судебной практике» [7]. «Нынешнее состояние законодательства о взаимном страховании и имеющейся правоприменительной практики по делам такого рода во многом обусловлено отсутствием традиций» - далее объясняет он [8]. В итоге, как отмечает Беженцева Э.А., «допущенные в Законе противоречия и отсутствие уточняющих норм, ...не позволяют им (обществам взаимного страхования - уточнено автором) стать той доступной и простой формой страховой защиты, которая могла бы с успехом решать соответствующие экономические и социальные задачи» $[9$, с. 40$]$.

Еще одну категорию внешних правовых рисков ОВС составляют риски, связанные с неисполнением или ненадлежащим исполнением договорных обязательств субъектами, с которыми ОВС имеет дело в силу необходимости обслуживания хозяйственных процессов и осуществления уставной деятельности. Поскольку ОВС - юридическое лицо, которое может иметь в собственности здания, строения, сооружения, оборудование и иное не запрещенное законодательством Российской Федерации имущество, требующее содержания и обслуживания, неизбежно привлечение к этому лиц, которые становятся для ОВС контрагентами. Таким образом, порождаются гражданско-правовые обязанности [10], которые контрагент, как носитель определенных обязательств, может не выполнить. Возникают так называемые договорные риски, которые минимизируются лишь тщательной селекцией поставщиков услуг и четким определением объема их ответственности. Однако, они актуальны не для всех, а лишь для крупных ОВС, имеющих такое имущество. В отличии от этого, риски, связанные с исполнением обязательств по договорам перестрахования, заключаемым со страховщиками, имеющими соответствующую лицензию, не зависят от численности и состава ОВС, а определяются самим фактом страхования риска страховой выплаты, принятого на себя обществом. Хотя факт перестрахования и может зависеть от объема принимаемой на себя обществом ответственности, определяемого в том числе и субъектностью OBC: естественно, что объем ответственности по рискам 5 физических лиц будет скорее всего меньше, чем объем ответственности 3 юридических лиц.

\section{Baikal Research Journal}

электронный научный журнал Байкальского государственного университета 
Внешние договорные риски ОВС могут возникать и в процессе инвестирования средств страховых резервов, если оно осуществляется путем передачи части средств в доверительное управление управляющей компании. Это могут быть риски признания договора доверительного управления недействительным, а также риски неисполнения или ненадлежащего исполнения обязательств по договору - они могут быть вызваны внесением в договоры несогласованных с юристами компании изменений, недобросовестными действиями или бездействиями со стороны субъектов правоотношений, а также форс-мажорными обстоятельствами, возникшими при исполнении договора. Заметим, что подобные правовые риски опосредуют возникновение финансовых рисков, а объем ответственности доверительного управляющего при этом определяется в соответствии с нормами статьи 1022 ГК РФ (часть II).

Анализируя деятельность ОВС, мы пришли к выводу о том, что их договорные связи не столь разнообразны, как у коммерческих страховщиков, которые в процессе андеррайтинга, урегулирования убытков и споров, формирования и реализации маркетинговой политики и продаж, обслуживания бизнес-процессов (иногда в формате аутсорсинга [11]) активно прибегают к услугам третьих лиц и организаций. Количество и содержание этих связей предопределяется целями создания общества. Добровольное объединение лиц для осуществления взаимного страхования своих имущественных интересов не требует привлечения страховых посредников, не нуждается в осуществлении рекламных кампаний, услугах медиаторов, омбудсменов, других представителей инфраструктуры страхового рынка. Исключение составляют лишь актуарии (их оценка является обязательной), чаще всего привлекаемые на условиях гражданско-правового договора об осуществлении актуарной деятельности.

Таким образом, зона внешней ответственности и встречных обязательств не столь активна, поэтому внешние договорные риски для ОВС не могут представлять какой-либо серьезной опасности при условии качественной юридической экспертизы договоров, заключаемых с третьими лицами.

В отличие от этого влияние внутренних договорных рисков на деятельность ОВС более существенно, но опять же при условии, если

1) уставом общества заключение договора страхования предусмотрено;

2) численность членов общества максимальна или приближена к ней (две тысячи физических лиц и (или) пятьсот юридических лиц).

Мы разделяем точку зрения Д. А. Архипова о том, что «под договорным риском следует понимать основанную на договоре вероятность возникновения у одной из сторон убытков и (или) иных отрицательных имущественных последствий, которые не могут быть предотвращены при проявлении той степени заботливости и осмотрительности, какая требуется от обеих сторон по характеру договора и условиям оборота» [12, с. 32]. Классифицируя универсальные договорные риски в страховании, можно выделить следующие их основные группы:

- риск признания договора страхования незаключенным;

- риск признания договора страхования недействительным;

- риск неисполнения или ненадлежащего исполнения договора страхования.

Все они (включая методы минимизации) достаточно подробно уже описывались нами ранее [4] и в полной мере могут быть применены к деятельности ОВС, поскольку Федеральным законом «О взаимном страховании» предусматривается заключение именно договора страхования.

Заметим, что между ОВС и его членами страховое обязательство может возникать и из устава и правил страхования. Уставом определяются вид или виды страхования, осуществляемые обществом, а также условия ответственности по страховым обязательствам общества и порядок несения членами общества такой

\section{Baikal Research Journal}

электронный научный журнал Байкальского государственного университета 
ответственности. Именно поэтому к его составлению необходимо подходить с той степенью тщательности и предусмотрительности, которая требуется по условиям делового оборота. В противном случае, внесение изменений в Устав потребует не только значительных организационных и временных, но и финансовых затрат, поскольку сопряжено с прохождением процедуры государственной регистрации.

Если взаимное страхование осуществляется непосредственно на основании устава общества, в таком случае только по одному виду страхования и без заключения договора (как правило, это оправданно при минимальной численности членов общества), то можно говорить о том, что внутренние договорные риски общества минимальны и сводятся лишь к рискам, опосредованным наличием трудовых договоров с персоналом (риски конфликта интересов, риски, связанные с возникновением трудовых споров и т.п).

Определенную угрозу для деятельности ОВС могут представлять и так называемые комплаенс-риски (в более привычном употреблении - регуляторные риски), в основе которых, как правило, лежит конфликт интересов сотрудников и общества (или органов его управления) и, как следствие, несоответствие их действий внутренним и внешним нормативным документам. Справедливо заметить, что в некоторых случаях возникновение регуляторных рисков не связано с преднамеренными действиями сотрудников, а бывает вызвано несовершенством правовых норм и документов (например, существованием неоднозначных толкований требований надзорных органов), несовершенством организационной структуры общества, неэффективностью внутреннего контроля, организованного в обществе. Некоторые авторы все многообразие причин возникновения регуляторных рисков свели к факторам объективного характера и факторам субъективного характера. Так, Ю. В. Трунцевский, подход которого нам представляется более основательным и полным, отмечает, что к объективным факторам необходимо отнести:

- позитивную неопределенность правовых норм и многообразие конкретных жизненных обстоятельств, ими регулируемых;

- объективное отставание права от развития общественных отношений;

- наличие областей общественных отношений, подпадающих под законодательное умолчание;

- специфику языка права;

- наличие логико-структурных дефектов права (пробелы, коллизии норм и коллизии интерпретаций, несовершенство юридических и терминологических конструкций и др.) [13, с. 118].

К субъективным факторам, по его мнению, относятся индивидуальные особенности субъектов толкования, выражающиеся в уровне его правосознания, правовом (профессиональном) опыте и иных личностных качествах; в фактической зависимости при формальной независимости от экономических, политических, ведомственных, индивидуальных и иных интересов [13, с. 119]. Все эти факторы, что весьма очевидно, в полной мере можно отнести и к деятельности ОВС.

Отметим, что правовые риски всегда связаны с привлечением субъекта к ответственности за допущенное нарушение. Кроме того, в отличие от иных видов рисков они пронизывают всю деятельность ОВС и проявляются при любых осуществляемых ими операциях и сделках. В данной статье представлены лишь наиболее актуальные и значимые из них, поэтому мы ни в коей мере не претендуем на полноту исследования, но смеем утверждать, что правовые риски, имеющие место быть в деятельности обществ взаимного страхования, обладают рядом следующих особенностей:

- они маловероятны для малочисленных ОВС, образованных из числа физических лиц и осуществляющих страхование исключительно на основании Устава

\section{Baikal Research Journal}

электронный научный журнал Байкальского государственного университета 
общества и наибольшую угрозу могут представлять лишь на стадии образования общества;

- наибольшую актуальность имеют для многосубъектных ОВС, образованных из числа юридических лиц, когда страхование строится на основании договорных отношений;

- они не столь разнообразны, как правовые риски страховых организаций;

- значительную угрозу для ОВС представляют внешние правовые риски ввиду подвижности правовой базы и отсутствия накопленного опыта правоприменительной практики;

- некоторые из них являются внутренними для ОВС, но внешними для страховых организаций (например, риски неисполнения или ненадлежащего исполнения обязательств перед страхователями, риски, основанные на отношениях с участием потребителей страховых услуг), ввиду отличий в юридической принадлежности к страховщику лиц, передающих риск на страхование;

- причины возникновения внутренних правовых рисков, как правило, субъективны, а значит, сами правовые риски могут быть достаточно легко минимизированы;

- страховое мошенничество как фактор правового риска ОВС практически не рассматривается, поскольку члены общества объединены общностью интересов, едиными целями и общей финансовой ответственностью.

Своевременная и полная идентификация правовых рисков способствует более эффективному построению политики риск-менеджмента ОВС, минимизации возможных потерь и обеспечению их устойчивого развития как полноправных участников страхового рынка.

\section{Список использованной литературы}

1. Русакова О. И. Страховая деятельность и ее регулирование на современном страховом рынке / Е. В. Андреева, О. И. Русакова. - Иркутск : Изд-во БГУЭП, 2015. - 160 с.

2. Газенкампф Т. К. Взаимное страхование в Российской Федерации на примере Иркутской области [Электронный ресурс] / Т. К. Газенкампф // Известия Иркутской государственной экономической академии. - 2011. - № 2. - Режим доступа: http://brjbguep.ru/reader/article.aspx?id=7744.

3. Гунин Е. М. Об особенностях правового положения и деятельности обществ взаимного страхования / Е. М. Гунин, Р. Д. Бахышов // Вестник Кемеровского государственного университета. - 2015. - Т. 2, № 4. - С. 217-220.

4. Степанова М. Н. Правовые риски в страховании : учеб. пособие / М. Н. Степанова. Иркутск : Изд-во БГУ, 2016. - 107 с.

5. Хитрова Е. М. Интересы участников страховых отношений и риски их реализации / Е. М. Хитрова // Бизнес. Образование. Право. Вестник Волгоградского института бизнеса. 2016. - № 1. - C. 136-140.

6. Жигас М. Г. Развитие страховых отношений на основе использования механизма саморегулирования [Электронный ресурс] / М. Г. Жигас // Известия Иркутской государственной экономической академии. - 2014. - № 4. - Режим доступа: http://brjbguep.ru/reader/article.aspx?id=19289.

7. Бартош В. М. Перестрахование на основе взаимности и с участием общества взаимного страхования / В. М. Бартош // Хозяйство и право. - 2009. - № 4. - С. 52-59.

8. Бартош В. М. Взаимное страхование: теория и практика применения / В. М. Бартош // Законодательство. - 2009. - № 4. - С. 55-63.

9. Беженцева Э. А. Взаимное страхование: ретроспектива и современность / Э. А. Беженцева // Развитие страхового рынка России в современных условиях : сб. науч. тр. - Иркутск : Изд-во БГУЭП, 2012. - С. 39-44.

10. Шемчук О. А. К вопросу о содержании гражданско-правовой обязанности / О. А. Шемчук // Известия Иркутской государственной экономической академии. - 2012. № 6. - Режим доступа: http://brj-bguep.ru/reader/article.aspx?id=16471.

\section{Baikal Research Journal}


11. Степанова М. Н. Аутсорсинг в деятельности страховых компаний как новое направление повышения эффективности бизнеса / М. Н. Степанова // Развитие страхового рынка России в современных условиях : сб. науч. тр. - Иркутск : Изд-во БГУЭП, 2014. C. $120-124$.

12. Архипов Д. А. Распределение договорных рисков в гражданском праве. Экономикоправовое исследование / Д. А. Архипов. - М. : Статут, 2012. - 112 с.

13. Трунцевский Ю. В. Правовые риски: понятие и виды [Электронный ресурс] / Ю. В. Трунцевский. - Режим доступа: http://kizilov-inc.ru/sites/default/files/gm_articles/ pravovye_riski_ponyatie_i_vidy.pdf.

\section{References}

1. Rusakova O. I., Andreeva E. V. Strahovaja dejatel'nost' i ee regulirovanie na sovremennom strahovom rynke [nsurance activity and its regulation on the current insurance market]. Irkutsk, Baikal State University of Economics and Law Publ., 2015. 160 p.

2. Gazenkampf T. K. Mutual insurance in the Russian Federation in terms of Irkutsk Oblast. Izvestija Irkutskoj gosudarstvennoj jekonomicheskoj akademii = Bulletin of Irkutsk State Economic Academy, 2011, no. 2. Available at: http://brj-bguep.ru/reader/article.aspx?id=7744. (In Russian).

3. Gunin E. M., Bahyshov R. D. [On features of legal situation and activity mutual insurance societies]. Vestnik Kemerovskogo gosudarstvennogo universiteta $=$ Bulletin of Kemerovo State University, 2015, vol. 2, no. 4, pp. 217-220. (In Russian).

4. Stepanova M. N. Pravovye riski $v$ strahovanii [Legal risks in insurance]. Irkutsk, Baikal State University of Economics and Law Publ., 2016. 107 p.

5. Khitrova E. M. Interests of participants of insurance relations and risks of their implementation. Biznes. Obrazovanie. Pravo. Vestnik Volgogradskogo instituta biznesa = Business. Education. Law. Bulletin of Volgograd Institute of Business, 2016, no. 1, pp. 136-140. (In Russian).

6. Zhigas M. G. Development of insurance relations on the basis of using self-regulation mechanism. Izvestija Irkutskoj gosudarstvennoj jekonomicheskoj akademii = Bulletin of Irkutsk State Economic Academy, 2014, no. 4. Available at: http://brj-bguep.ru/reader/article.aspx?id=19289. (In Russian).

7. Bartosh V. M. Reassurance on the basis of mutuality and with participation of mutual insurance society. Hozjajstvo i pravo = Economy and Law, 2009, no. 4, pp. 52-59. (In Russian).

8. Bartosh V. M. Mutual insurance: theory and practice of application. Zakonodatel'stvo = Legislation, 2009, no. 4, pp. 55-63. (In Russian).

9. Bezhenceva Je. A. Mutual insurance: retrospective and modern times. Razvitie strahovogo rynka Rossii $v$ sovremennyh uslovijah [Development of insurance market in Russia in current environment]. Irkutsk, Baikal State University of Economics and Law Publ., 2012, pp. 39-44. (In Russian).

10. Shemchuk O. A. On issue of content of civil and legal liability. Izvestija Irkutskoj gosudarstvennoj jekonomicheskoj akademii = Bulletin of Irkutsk State Economic Academy, 2012, no. 6. Available at: http://brj-bguep.ru/reader/article.aspx?id=16471. (In Russian).

11. Stepanova M. N. Outsourcing in insurance companies' activity as a new direction of increasing business efficiency. Razvitie strahovogo rynka Rossii $v$ sovremennyh uslovijah [Development of insurance market in Russia in current environment]. Irkutsk, Baikal State University of Economics and Law Publ., 2014, pp. 120-124. (In Russian).

12. Arhipov D. A. Raspredelenie dogovornyh riskov v grazhdanskom prave. Jekonomiko-pravovoe issledovanie [Distribution of contract risks in civil law. Economic and legal research]. Moscow, Statut Publ., 2012. 112 p.

13. Truncevskij Ju. V. Pravovye riski: ponjatie i vidy [Legal risks: concept and types]. Available at: http://kizilov-inc.ru/sites/default/files/gm_articles/pravovye_riski_ponyatie_i_vidy.pdf.

\section{Информация об авторе}

Степанова Марина Николаевна - кандидат экономических наук, доцент, кафедра «Страхование и управление рисками», Байкальский государственный университет, 664003, г. Иркутск, ул. Ленина, 11, e-mail: emarina77@list.ru.

\section{Baikal Research Journal}




\section{Author}

Marina N. Stepanova - PhD in Economics, Assistant Professor, Chair of Insurance and Risk Management, Baikal State University, 11 Lenin St., 664003, Irkutsk; e-mail: emarina77@ list.ru.

\section{Для цитирования}

Степанова М.Н. Правовые риски обществ взаимного страхования: понятие и особенности / M. Н. Степанова // Baikal Research Journal. - 2017. — T. 8, № 3. - DOI : 10.17150/24116262.2017.8(3).3.

\section{For citation}

Stepanova M. N. Legal Risks of Mutual Insurance Companies: Concept and Features. Baikal Research Journal, 2017, vol. 8, no. 3. DOI: 10.17150/2411-6262.2017.8(3).3. (In Russian).

\section{Baikal Research Journal}

